\title{
Modality, weights, and inconsistent premise sets*
}

\author{
Alex Silk \\ University of Michigan \\ “'May', 'Ought', and 'Must' — they are contemptible auxiliaries." \\ George Eliot ${ }^{\dagger}$
}

\begin{abstract}
This paper investigates two types of data that appear to motivate complicating the semantics for weak necessity modals. I argue that these data can be captured using the same conceptual resources within a conservative extension of the standard quantificational semantics. The resulting analysis illuminates previously puzzling and underappreciated semantic and pragmatic properties of weak and strong necessity modals, and clarifies the special role that expressions of weak necessity play in conversation, deliberation, and planning.
\end{abstract}

Keywords: Modality $\bullet$ Priorities $\bullet$ Weak necessity modals $\bullet$ Strong necessity modals

\section{Introduction}

In this paper I will discuss two types of linguistic phenomena that appear to motivate complicating the semantics for modals like 'ought' and 'should'.

First, these modals appear to be sensitive to the strengths of various ideals. Suppose your only goals are to go for a run (now) and to watch a movie (now). You can't do both, but you want to run much more than you want to watch a movie. Call this case 'WEIGHTED GoALs'. Intuitively, (1) is true and (2) is false.

(1) In view of your goals, you should (/ought to) go for a run.

(2) In view of your goals, you should (/ought to) watch a movie.

Some have argued that standard analyses of modals cannot capture these intuitions, or at least that they are silent about how to do so.

Second, intuitively, 'Should $\phi$ ' and 'Ought $\phi$ ' express that $\phi$ is necessary in some sense. Yet it is well established that though 'should' and 'ought' ("weak necessity modals") are stronger than possibility modals like 'may' or 'can', they

*Thanks to Nate Charlow, Dan Greco, Irene Heim, Dan Lassiter, Dan Singer, Bob Stalnaker, Eric Swanson, Rich Thomason, and participants at SALT 22 for helpful discussion.

${ }^{\dagger}$ Mary Garth, in Middlemarch, Bk. 2, Ch. 14. Slightly modified from the original. 
are nevertheless weaker than modals like 'must' and 'have to' ("strong necessity modals"). ${ }^{1}$ (For the purposes of this paper I will not distinguish between the meanings of 'ought' and 'should', on the one hand, or between 'must' and 'have to', on the other. What I say for 'should' holds for 'ought', and similarly for 'must' and 'have to'.) What is not well established is how to capture this difference in strength.

a. I should help the poor. In fact, I must.

b. I must help the poor. \#In fact, I should.

a. I should help the poor, but I don't have to.

b. \#I must help the poor, but it's not as if I should.

'Should' allows strengthening to 'must', as in (3a), but not vice versa, as reflected in (3b). Similarly, (4a) is consistent in a way that (4b) is not. But if 'should' and 'must' both express necessity, treated as universal quantifiers over worlds, it is unclear how to capture this difference in strength.

Though on first glance these phenomena may appear unrelated, I will argue that they can be captured using the same conceptual resources within an extension of the standard quantificational semantics. The resulting analysis, I hope, will illuminate previously puzzling and underappreciated semantic and pragmatic properties of weak and strong necessity modals, and clarify the special role that expressions of weak necessity play in conversation, deliberation, and planning.

\section{The classical semantics}

On the classical semantics for modals, as made well known by Angelika Kratzer (1977, 1981a, 1991), modals are treated as context-dependent quantifiers over possible worlds. The domain of quantification is set by two contextually supplied parameters: a set $f$ of accessible worlds (a "modal base"), and a preorder $\lesssim$ (a reflexive and transitive relation) on $W$. Roughly, modals can be treated as quantifying over the worlds in the modal base that rank highest in the preorder. ${ }^{2}$

Different readings of modals arise from different contextual resolutions of the modal base and preorder. Modal bases determine reflexive accessibility relations: they are sets of propositions describing a body of relevant circumstances or evidence

\footnotetext{
${ }^{1}$ See, e.g., Sloman 1970; Horn 1972, 1989; Wertheimer 1972; Harman 1975, 1993; Lyons 1977; Williams 1981; Coates 1983; Jones \& Pörn 1986; Bybee, Perkins \& Pagliuca 1994; McNamara 1996; Palmer 1990, 2001; Copley 2006; von Fintel \& Iatridou 2008.

${ }^{2}$ See also van Fraassen 1973; Lewis 1973; Veltman 1976. I sometimes use 'modal base' to refer to a set of propositions, sometimes to the intersection of this set; I trust that context will disambiguate. For simplicity I make the limit assumption (Lewis 1973: 19-20) and assume that there are $\lesssim$ best (or tied for best) worlds. For semantics without the limit assumption, see Lewis 1973; Kratzer 1981a, 1991; Swanson 2011.
} 
Modality, weights, and inconsistent premise sets

in the world of evaluation. The preorders are generated by an ordering source $g(w)$ - a set of propositions indexed to the world of evaluation - in the following way: for any worlds $w^{\prime}$ and $w^{\prime \prime}, w^{\prime}$ is at least as good as $w^{\prime \prime}$ relative to the ideal set up by $g(w)$ iff all propositions in $g(w)$ that are true in $w^{\prime \prime}$ are also true in $w^{\prime}$.

Definition $1 w^{\prime} \lesssim_{g(w)} w^{\prime \prime}:=\forall p \in g(w): w^{\prime \prime} \in p \rightarrow w^{\prime} \in p$

An ordering source describes the content of some ideal (e.g., the law, morality, your goals, the usual course of events).

Given a preordered set $\left(W, \unlhd_{g(w)}\right)$, a selection function $D$ can be defined to select from some domain those worlds that are not $\lesssim_{g(w)}$ bettered by any other world.

Definition $2 \forall Z \subseteq W: D\left(Z, \varsigma_{g(w)}\right):=\left\{w^{\prime} \in Z: \forall w^{\prime \prime} \in Z: w^{\prime \prime} \lesssim_{g(w)} w^{\prime} \Rightarrow w^{\prime} \lesssim_{g(w)} w^{\prime \prime}\right\}$

$D$ selects the set of $\lessgtr_{g(w)}$ best worlds from the modal base, those worlds in the modal base that best approximate the relevant ideal. Modals quantify over these worlds in $D\left(\cap f(w), \Sigma_{(w)}\right)$. Treating 'should' as expressing necessity, the truth conditions for 'Should $\phi$ ' are as follows.

Definition 3 [Should $\phi \rrbracket^{c, w}=1$ iff $\forall w^{\prime} \in D\left(\cap f(w), \varsigma_{g(w)}\right): \llbracket \phi \rrbracket^{c, w^{\prime}}=1$

This says that 'Should $\phi$ ' is true iff ' $\phi$ ' is true at all the $\lesssim_{g(w)}$ best accessible worlds.

\section{Weights and priorities}

Cases like WEIGHTED GOALs pose a prima facie problem for the standard semantics. It might seem that WEIGHTED GOALs calls for an ordering source like in (5) that describes the contents of your goals. (I use italics to denote propositions, conceived as sets of worlds.)

$$
g(w)=\{\text { You go for a run, You watch a movie }\}
$$

Simplifying a bit, suppose the (circumstantial) modal base consists of the worlds (or representatives of relevant equivalence classes of worlds) $R$ and $M$, where you go for a run in $R$ and watch a movie in $M$. Since you cannot simultaneously go for a run and watch a movie, there is no world in the modal base in which both of your goals are satisfied. Thus, by Definition $1, R$ and $M$ are $\lesssim_{g(w)}$ incomparable (and $\lessgtr_{g(w)}$ best): $R \in\{$ You go for a run $\}$ and $M \in\{$ You watch a movie $\}$, but neither $\{$ You go for a run $\}$ nor $\{Y o u$ watch a movie\} is a subset of the other. By Definition 3, this incorrectly predicts that both (1) and (2) are false: it's not the case that in both $R$ and $M$ you go for a run or that in both of them you watch a movie. The problem is that there seems to be no way of representing the different strengths of your goals. 'Should' sentences are evaluated with respect to maximally consistent subsets of 
$g(w)$ and no mechanism can "break the tie" between $\{$ You go for a run $\}$ and $\{$ You watch a movie\}.

Some have taken this problem to be insurmountable for the standard semantics. Here is Lassiter: "The problem is fundamentally that [Kratzer's] theory makes no room for one [goal's] being stronger than another; instead any conflict of [goals] leads to incomparability"; "the theory doesn't leave any room for [one goal's] being stronger or weaker than another... [Goals] are all-or-nothing" (2011: 61-62, 63-64, adapted for the case of teleological modals; $c f .148-149,179)$. I will argue that this problem is merely apparent. ${ }^{3}$

Intuitively it is clear what the preorder called for in WEIGHTED GOALs should look like: $R$ should be ranked higher than $M$. Given the equivalence of ordering semantics and premise semantics (Lewis 1981), we can be assured that there is some set of propositions that induces this ordering and reflects these priorities ( $c f$. Lewis 1981: 220-221; Kratzer 1981b: 210). The question, of course, is whether we can find a non-ad hoc way of determining what this set of propositions is.

The problem, I suggest, is that we do not have a nuanced enough characterization of the contents of your goals. Typically our goals are not to do such-and-such no matter what. Norms, desires, goals, and the like do not usually come in the form of blunt Kantian categorical imperatives or divine commands - in the case of WEIGHTED GOALS, something like Go for a run, no matter what! or Watch a movie, no matter what!. Rather they often come with (what I will call) "applicability conditions" ("ACs," for short); they can be hypothetical, or prima facie (cf. Ross 1930, Hare 1952, Kant 1956). For instance, in the moral case, a premise that describes a prohibition against lying need not be categorical, something like You never lie. Instead it might be conditional on the absence of certain defeating conditions, e.g., something like Unless not lying would lead to an innocent person's death or some other serious harm or..., you do not lie. In the bouletic case, our preferences are often conditional, preferences for certain circumstances. Very roughly, in WEIGHTED GOALS the ordering source might be more accurately represented by something as in (6), or, more schematically, as in (7), where $C$ describes the relevant applicability conditions, the conditions under which — and, in this case, only under which — the goal in question is to be pursued. ${ }^{4}$

\footnotetext{
${ }^{3}$ One initially plausible way of revising the standard semantics to capture priorities might involve introducing a weighting relation $\varsigma_{w}^{g(w)}$ that ranks the propositions in the ordering source. I will not consider this type of analysis since I will argue that such complications - and surely more, were this strategy pursued - are not necessary to capture the data.

${ }^{4}$ The first premise might be more precisely represented thus: $[\lambda w$. You go for a run in $w \leftrightarrow$ there is no action $\alpha$ such that $(a)$ you cannot both run and $\alpha$ in $w$ and $(b)$ you prefer to $\alpha$ more than you prefer to run in $w$ ]. There may be reasons for separating the biconditional into two premises, i.e., two material conditionals of the form $C \rightarrow \phi$ and $\neg C \rightarrow \neg \phi$.
} 
Modality, weights, and inconsistent premise sets

$$
\begin{array}{ll}
\text { (6) } \quad & g(w)= \\
& \{\text { You go for a run } \leftrightarrow \text { you don't prefer to do anything else more, } \\
& \text { You watch a movie } \leftrightarrow \text { you don't prefer to do anything else more }\} \\
& g(w)= \\
& \{\text { You go for a run } \leftrightarrow C, \\
& \text { You watch a movie } \left.\leftrightarrow C^{\prime}\right\}
\end{array}
$$

So, rather than introducing a semantic mechanism that weights categorical propositions in the ordering source, we can capture these weights by encoding relevant features of the priorities in question into the premises themselves - specifically, into the norms' ACs. (Unconditional premises can be treated as having $W$ as their AC.)

An ordering source like the one in (6) generates the correct results in WEIGHTED GOALS. Given that one of the relevant circumstances is that you want to go for a run more than you want to watch a movie, $C$ but not $C^{\prime}$ will be satisfied throughout the circumstantial modal base. Accordingly $R$ is $\lesssim_{g(w)}$ better than $M$, by Definition $1-R$ verifies both propositions in the ordering source, whereas $M$ verifies neither proposition - and we correctly predict that (1) is true and (2) is false.

Though all of the propositions in the ordering source figure into the interpretation of the modal, some of them may do so only trivially. If their ACs are not met, they may be vacuously satisfied throughout the modal base, and so will not distinguish among these worlds. This captures the intuitive idea that given the relevant circumstances - that is, given which premises have their ACs met - only certain relevant norms, goals, etc. are "in force."

Of course it remains to be seen whether this strategy will generalize to more complex cases. But insofar as we have clear intuitions about what preorders are called for, I am optimistic that more nuanced characterizations of the ACs for the norms, goals, etc. in question may yield the correct results. To be sure, in ordinary conversations it may be underdetermined precisely what these ACs are. But this is just one more way in which modal expressions can be vague.

\section{Weak necessity and secondary ordering sources}

In the remainder of this paper I will argue that applicability conditions play a crucial role in capturing certain aspects of the weak/strong necessity distinction.

As we saw in (3)-(4), 'must' appears to be logically stronger than 'should'. 'Must $\phi$ ' asymmetrically entails 'Should $\phi$ '. To capture this, one might treat weak necessity modals as 'most'-quantifiers, as only quantifying over most of the best worlds as opposed to all of them. However, as von Fintel \& Iatridou (2008: 118) note, our semantics should not presuppose that there are finitely many worlds or that we can count them ( $c f$. Copley 2006). 
Instead von Fintel \& Iatridou $(2005,2008)$ take up the plausible idea from Sloman (1970) that weak necessity modals quantify over "the best of the best" worlds, the $\lesssim_{g(w)}$ best worlds that are also best by some additional measure. Whereas weak necessity modals "[pick] out the best means without excluding the possibility of others," strong necessity modals "[imply] that no other means exist" (Sloman 1970: 390-391). As Bernard Williams puts it, "Ought is related to must as best is related to only" (1981: 125). (8), they claim, conveys that there are multiple ways of getting to Harlem but that taking the A train is best by some additional measure.

To go to Harlem, you should take the A train.

Saying that you should take the A train to go to Harlem because it's quickest is, on this view, the same as saying that you must take the A train to go to Harlem in the quickest way.

Developing a suggestion of Kratzer's (1981a: 72), von Fintel \& Iatridou implement this idea by introducing a secondary ordering source $g^{\prime}(w)$ that refines the initial preorder $\lesssim_{g(w)}$. Whereas strong necessity modals (universally) quantify over the $\lesssim_{g(w)}$ best worlds, weak necessity modals (universally) quantify over a subset of these worlds, the $\lesssim_{g(w)}$ best worlds that are also best in view of $g^{\prime}(w)$ — to a first ap-

proximation and using our notation, over the worlds in $D\left(D\left(\cap f(w), g_{g(w)}\right), \S_{g^{\prime}(w)}\right)$. (See their 2008: 138n.35 for potential refinements.) In the case of (8), the primary ordering source might be something like $\{$ You go to Harlem $\}$, and the secondary ordering source might be something like \{You take the quickest route when traveling\}.

Though this analysis captures how 'should' is weaker than 'must' while avoiding counting worlds, there is something unsatisfying about it. Little is said about what makes a primary ordering source "primary" and a secondary ordering source "secondary" apart from the fact that the latter figures into the interpretation of weak but not strong necessity modals. No story is given about how primary and secondary ordering sources are determined independently of the truth conditions of the relevant 'should' and 'must' sentences, that is, in a manner that does not simply involve reverse engineering them from relevant truth value judgments.

\section{Weak necessity as conditional necessity}

It is well appreciated that a primary goal of conversation is to share information, to coordinate on how the world is. We often express our beliefs about the world and invite others to share in these beliefs. But we also express other aspects of our states of mind. We coordinate on our expectations, values, goals, plans, feelings. In the case of belief, sometimes we assert propositions outright. In doing so, we 
Modality, weights, and inconsistent premise sets

commit to settling on the truth of our assertion for the remainder of the conversation. ${ }^{5}$ But sometimes we do not want to impose such a strong restriction on the future course of the conversation. Perhaps we want to propose that we coordinate on $\phi$, but we do not know precisely on what terms our interlocutor could reasonably accept that $\phi$. Or perhaps we wish to plan as if $\phi$ but are not sure that certain (plausible) assumptions required for the truth of $\phi$ are satisfied. It would be surprising if we did not develop the linguistic means of carrying out these goals, making such proposals, or expressing such states of mind.

Fortunately we did: I suggest that it is precisely this hedging role that weak necessity modals play in conversation, deliberation, and planning. I agree with von Fintel \& Iatridou that the distinction between weak and strong necessity modals is in part truth-conditional; however, I will argue that the primary difference between them concerns the modal base rather than the ordering source, specifically, the relation between the modal base and the relevant set of applicability conditions.

\subsection{The analysis}

As Aynat Rubinstein (2011, 2012a,b) has highlighted in a rich body of recent work, the relative felicity of weak and strong necessity modals interestingly depends on standing assumptions in the context ( $c f$. von Stechow, Krasikova \& Penka 2006: 14-15; von Fintel \& Iatridou 2008: 139-140. I will return to her view in §6). Suppose I am considering whether to fight in the Resistance or take care of my ailing mother. I mention that the value of family, which supports my helping my mother over my fighting, is important to me. Your communicating that my helping my mother is deontically necessary depends on how the status of this value and other values figure in the common ground (cf. Rubinstein 2011: 141).
a. Me: Family is very important.
You: I agree. You should ('must) take care of your mother.
b. Me: Family is most important - more important than country.
You: I agree. You must (? should) take care of your mother.

The necessity of my helping my mother depends on the value of family being more important in this context than other potentially competing values. The weak necessity 'should' is felicitous only if this condition is not currently established in the conversation, as in (9a). But once this condition becomes common ground, it is 'must', not 'should', that is preferred, as in (9b).

\footnotetext{
${ }^{5}$ As usual, I assume as an idealization a purely monotonic model of information gathering, i.e., that information is only added and, once added, is not subject to further discussion.
} 
Let's clarify precisely what the modal bases and ordering sources are in (9). One initially plausible thought is that the relevant difference in context after my utterance in (9a) and (9b) concerns the value of the ordering source, specifically, whether the value of family is represented ( $c f$. Rubinstein 2011: 141, 146; 2012a). But this doesn't seem right. My utterance in (9a) expresses my endorsement of the value of family, which you acknowledge.

Instead, the relevant contextual difference, I suggest, concerns the modal base. It concerns the status of a certain fact, namely, whether there might be competing values and, if there are, how to rank their relative importance. My utterance in (9a) does establish in the common ground the value of family, but, as our discussion in $\S 3$ suggests, this value is conditional. In both (9a) and (9b) it is accepted that the value of family is to be promoted given that certain defeating conditions do not obtain; the conversationally agreed upon value of the ordering source may be the same in both cases. Roughly (see n. 4):

$$
\begin{aligned}
& g(w)=\{I \text { help my mother } \leftrightarrow \text { there are no more important countervailing } \\
& \text { values }\}
\end{aligned}
$$

What is not settled in (9a), but which is settled in (9b), is whether the applicability condition $C$ for my promoting the value of family is satisfied.

This discussion highlights two important properties of weak necessity modals. First, in (9a), though the deontic necessity of my helping my mother depends on the assumption that $C$ is true, an assumption not settled in the context, your 'should' claim is still felicitous and true. (If the modal base does not get restricted to $C$ worlds, there will be $\neg C$-worlds in which I do not help my mother that are $\lesssim g(w)$ best; they will verify both propositions in $g(w)$.) Second, even though the modals in (9a) and (9b) are deontic, the difference in their interpretation lies not in the ordering source but in the modal base. (We will return to example (9) in §5.2.3.)

I suggest that herein lie the important differences between weak and strong necessity modals. Roughly, whereas 'must' expresses necessity in the ordinary sense (as described in Definition 3), 'should' is used to make a conditional claim, a claim about what would be necessary were certain conditions to turn out to be satisfied. More specifically, 'must' implies (presupposes, implicates) that the ACs of certain relevant norms, goals, etc. are satisfied, whereas 'should' makes a subjunctive claim about what would be necessary in the relevant sense were those ACs to be satisfied (which they might be; I return to this point below). 'Should $\phi$ ' is true iff 'Must $\phi$ ' would be true were it to turn out that the relevant ACs - the ACs which must be true in order for $\phi$ to be necessary in the relevant sense - are satisfied. ${ }^{6}$ More formally, for an ordering source $g(w)$, let $C_{g(w)}$ be a (possibly improper) subset of the set of

${ }^{6}$ Cf. Palmer 2001: 32, 73-74, 184. 
Modality, weights, and inconsistent premise sets

ACs for each of the premises in $g(w)$.

$$
\begin{aligned}
& \text { ACTUAL STRONG } \\
& \qquad \text { Must } \phi \rrbracket^{c, w}=1 \text { iff } \forall w^{\prime} \in D(\cap f(w), \lesssim g(w)): \llbracket \phi \rrbracket^{c, w^{\prime}}=1 \\
& \text { SUBJUnCTIVE WEAK } \\
& \qquad \text { SShould } \phi \rrbracket^{c, w}=1 \text { iff } \forall w^{\prime} \in D\left(\cap\left(f(w) \cup C_{g(w)}\right), \lesssim_{g(w)}\right): \llbracket \phi \rrbracket^{c, w^{\prime}}=1
\end{aligned}
$$

As we will see, treating weak necessity modals as conditional in this way helps capture how they are well suited to play the sort of role in conversation, thought, and planning discussed in the beginning of this section. In uttering 'Must $\phi$ ' we propose that $\phi$ is necessary with respect to certain premises, e.g., those describing our evidence, norms, goals, etc. But sometimes such a proposal is inapt. Perhaps we are unsure whether all the relevant norms or goals apply. Or perhaps we are sure about this ourselves but take this matter to be controversial; we may be unsure whether our interlocutor could reasonably take our background assumption that they do apply on board. Or perhaps we do not wish to settle on some particular set of ACs as being common ground. More generally, perhaps we do not wish to restrict the future development of the conversation in such a way that decisively settles on the truth of certain ACs. Nevertheless we may still wish to propose to coordinate on the necessity of $\phi$. We can do so using a weak necessity modal: In uttering 'Should $\phi$ ', we can express our commitment to the necessity of $\phi$ on some implicit condition or other, and invite our interlocutor to test whether this same property holds of her cognitive state. If it does, we can then coordinate on proceeding as if $\phi$ is necessary while remaining open to new evidence about whether the relevant ACs are satisfied, or even neutral on what the relevant ACs are. If we decide that no such relevant ACs are satisfied - more precisely, that no relevant sets of ACs are jointly satisfiable in context - we can then change our plans and expectations without having to dramatically repair the context like we would if we had accepted 'Must $\phi$ '. If we accept 'Must $\phi$ ' and then come to deny that the ACs required for it to be true are satisfied, we must retract both our commitments to 'Must $\phi$ ' and to these ACs. But if we only accept 'Should $\phi$ ', we need only retract this commitment; any relevant ACs were accepted only suppositionally.

This way of understanding weak and strong necessity illuminates the roles of primary and secondary ordering sources in von Fintel \& Iatridou's analysis. As they note in passing, using a weak necessity modal "brings with it an element of tentativeness: the speaker is not saying that the secondary ordering source is something that has to be obeyed" (2008: 139). My semantics directly captures this tentativeness by treating 'should' as expressing a conditional commitment, as expressing that one is hypothetically treating certain possibly negotiable assumptions as if they were non-negotiable ( $c f .140)$. A point of contrast, though, is that whereas von Fintel 
\& Iatridou locate the weak/strong necessity distinction in the ordering source, I have located it in the modal base. On my analysis, just like in the interpretation of conditionals, only the modal base is updated or restricted in the interpretation of 'should'.

\subsection{Advantages}

\subsubsection{Counterfactual marking}

A surprising data point highlighted in von Fintel \& Iatridou 2008 is that in a wide variety of languages weak necessity can be expressed by combining a strong necessity modal with counterfactual morphology ( $c f$. Palmer 2001: 73, 127, 155, 183-184, 193-196, 203-204). ${ }^{7}$ It is speculated that "the counterfactual marking is co-opted here in a somewhat meta-linguistic kind of way: 'if we were in a context in which the secondary ordering source was promoted, then it would be a strong necessity that..." (139). One might worry that, absent an account of what makes it the case about a speaker that she is counterfactually promoting a secondary ordering source, this story about the role of the counterfactual marking is ad hoc.

The analysis in this paper may offer a more natural explanation. Roughly, on my analysis, 'Should $\phi$ ' is true iff $\phi$ would be necessary were it to turn out that such-and-such ACs are satisfied. In uttering 'Should $\phi$ ' one brackets whether certain assumptions are satisfied and makes a claim about what would be accepted to be necessary were we to move into an epistemically possible extension of the current context that settles that they do hold. This subjunctive element is built directly into the truth conditions for weak necessity modals.

It is important to see, however, that, as correctly predicted by the truth conditions in SUBJUNCTIVE WEAK, weak necessity modals cannot be used to make genuinely counterfactual claims. We cannot use 'should' when it is settled that the relevant ACs are not satisfied. In the context given for (9), if you know that the AC for my promoting the value of family is not satisfied, you cannot truly utter

$$
\text { \#You should take care of your mother. }
$$

(11) cannot be used to mean that if, contrary to fact, the AC for my helping my mother was satisfied, I would have to help my mother. For here you are in a position to make a true 'must' claim that is not counterfactual, i.e., 'You must not help your mother'. Given the role that necessity claims play in actually guiding action, deliberation, and expectations, it would be counter to our discourse- and non-discourse-related goals if weak necessity modals could make genuinely counterfactual claims. The

\footnotetext{
${ }^{7}$ As they note, English 'ought' fits this pattern historically: It was formerly the past subjunctive of the verb 'owe' (2008: 126n.22).
} 
Modality, weights, and inconsistent premise sets

truth conditions in SUBJUNCTIVE WEAK capture this.

This point is consistent with research on counterfactual marking. It is well known that counterfactual marking need not signal genuine counterfactuality (see, e.g., Anderson 1951; Stalnaker 1975; Iatridou 2000).

a. If you had the flu, which you do, you would have exactly the symptoms you have now.

b. If you took the 2:00 flight tomorrow, you would get there by 4:00.

In certain uses of the subjunctive, the speaker may simply wish to admit the possibility that it could become taken for granted that the marked sentence is not true. This, I have suggested, is what happens with weak necessity modals regarding the status of certain ACs.

\subsubsection{Asymmetric entailments}

The truth conditions in ACTUAL STRONG and subJUnctive WEAK capture that 'must' is logically stronger than 'should'. 'Must' quantifies over the maximal elements of $\lesssim g(w) \cap(\bigcap f(w))^{2}$, whereas 'should' quantifies over the maximal elements of the subpreorder $\lesssim_{g(w)} \cap\left(\cap\left(f(w) \cup C_{g(w)}\right)\right)^{2}$, for some value of $C_{g(w)}$. (For a set $S$, its Cartesian square $S^{2}=S \times S=\{\langle x, y\rangle: x \in S \wedge y \in S\}$.) When $C_{g(w)}$ is the empty set, these domains of quantification are identical. So, if 'Must $\phi$ ' is true, there is some $C_{g(w)}$ - e.g., $C_{g(w)}=\emptyset-$ such that all the $\lesssim g(w)$ best worlds in $\bigcap\left(f(w) \cup C_{g(w)}\right)$ are $\phi$-worlds; hence 'Should $\phi$ ' is true. But even if 'Should $\phi$ ' is true, 'Must $\phi$ ' will be false if there is some world $w^{\prime} \in D\left(\cap f(w) \backslash \cap\left(f(w) \cup C_{g(w)}\right), \lesssim g(w)\right): \llbracket \phi \rrbracket^{c, w^{\prime}}=0-$ that is, if there is some $\neg \phi$-world $w^{\prime}$ such that, for some $C_{g(w)}$ : (i) $w^{\prime}$ is in $\bigcap f(w)$; (ii) $w^{\prime}$ is not in the subset $\cap\left(f(w) \cup C_{g(w)}\right)$; and (iii) $w^{\prime}$ is not $\lesssim_{g(w)}$ bettered by any world in $\bigcap\left(f(w) \cup C_{g(w)}\right)$. So, if 'Must $\phi$ ' is true according to ActUal Strong, then 'Should $\phi$ ' is true according to SUBJUNCTIVE WEAK, but not vice versa.

This helps explain the cancelability data in (3). Since 'should' is logically weaker than 'must', Grice's first quantity maxim can be exploited to yield an upperbounding implicature, namely, from the use of 'should' that for all I know, or for all I am willing to presuppose for the purposes of the conversation, 'not must'. ${ }^{8}$ Specifically, in using 'should' the speaker implicates that certain ACs required for $\phi$ to be necessary are merely compatible with her beliefs. This scalar implicature has the usual properties associated with implicatures. It is cancelable and reinforceable, as we saw in (3a) and (4a), respectively. And it is suspendable and tends to vanish in non-assertive contexts, as seen in (13) and (14), respectively.

${ }^{8}$ See, e.g., Horn 1972, 1989; Gazdar 1979; Gamut 1991. 
(13) I should help the poor. Maybe I have to.

(14) a. I doubt that you should help the poor.

b. It's not as if you should help the poor.

\subsubsection{Relative felicity in conversation}

Let's apply the analyses in ACTUAL STRONG and SUBJUNCTIVE WEAK to our examples in (9). Start with (9b), where 'must' is preferred. After my assertion is accepted it becomes common ground that no other values might outweigh the value of family. So, assuming that the relevant ordering source is as given in (10), the AC for my helping my mother is satisfied throughout the modal base and your 'must' claim is true. Since using 'must' is felicitous in this context, using the weaker 'should' would violate a Gricean quantity maxim and so is dispreferred.

Next, consider (9a). After my assertion is accepted it is still not common ground that the AC for my helping my mother is satisfied. But assuming that this $\mathrm{AC}$ is at least compatible with the common ground, 'should' will be acceptable. Will it be preferred? That depends. Though we have said that 'should' is preferred in (9a), it is important to see that in certain contexts 'must' may be acceptable. A speaker may felicitously use 'must' in a context in which it is not common ground whether certain relevant ACs are satisfied if she can be presumed to be a legitimate authority on the truth of these ACs on which the necessity of the prejacent depends and can thus make them common ground by her utterance. This, of course, is a familiar kind of accommodation (Lewis 1979; Stalnaker 2002). Suppose Alice, a young teenager, wants to go to Harlem and is considering with her mother, Martha, about whether to take the $\mathrm{A}$ train or the $\mathrm{C}$ train. The $\mathrm{A}$ train will be quicker, but the $\mathrm{C}$ train will be safer. Martha takes the safety of her child to be of paramount importance, though this value is not common ground between them. Nevertheless Martha can felicitously say to Alice:

(15) You must take the $\mathrm{C}$ train, not the A train.

By uttering (15), Martha expresses her acceptance that the goal of traveling safely takes priority over the goal of traveling quickly. Given her authority in the context, she can legitimately expect Alice to share this acceptance, rendering it common ground that the $\mathrm{AC}$ of the former but not the latter goal is satisfied; she may have the authority to make Alice accommodate. Such special contexts notwithstanding - contexts in which the speaker does not have or does not wish to exercise this authority — 'should' will be preferred.

We saw in WEIGHTED GOALs that the interpretation of 'should' can be sensitive to priorities among relevant ideals. We can now see that this sensitivity is not unique to 
Modality, weights, and inconsistent premise sets

'should'. Were it settled that my desire to go for a run will not be outweighed by any stronger desire - a rather risky assumption in most contexts, given the variability in desires over time — using 'must' in (1) would be acceptable.

I have said that 'Should $\phi$ ' is true iff there is some live set of relevant ACs with respect to which 'Must $\phi$ ' is true. This might seem to be too weak a condition. If alternative ACs $C$ and $C^{\prime}$ are compatible with my beliefs, uttering 'Should $\phi$ ' when the necessity of $\phi$ depends on the truth of $C$ rather than $C^{\prime}$ seems to express one's relative endorsement of $C$ over $C^{\prime}$. One could build this subjective element into the semantics, but that would be unnecessary. We can derive it pragmatically. Upon hearing an utterance of 'Should $\phi$ ' a hearer might reason as follows:

" $S$ said 'Should $\phi$ '. So $S$ must think there is some live $C_{g(w)}$ with respect to which 'Must $\phi$ ' would be true. If $S$ thought there was another live $C^{\prime}{ }_{g(w)}$ with respect to which 'Must $\psi$ ' would be true (for contraries ' $\phi$ ' and ' $\psi$ ') such that she assigns a higher probability to $\cap C^{\prime}{ }_{g(w)}$ than to $\bigcap C_{g(w)}$, she would think 'Must $\psi$ ' was more likely to be true than 'Must $\phi$ '. So $S$ would have said 'Should $\psi$ ', assuming that she is being cooperative and obeying the maxims - especially, that given a set of alternative propositions she asserts the one she thinks is most likely to remain accepted throughout the evolution of the conversation. But $S$ didn't say 'Should $\psi$ '. So she must think $\cap C_{g(w)}$ is at least as likely as any relevant alternative set of ACs with respect to which 'Should $\psi$ ' would be true."

So it seems that we can retain our truth conditions in SUBJUNCTIVE WEAK while capturing how a speaker's assessments of the relative likelihoods of alternative sets of ACs can affect which 'should' claims she should assert and accept.

\subsubsection{Moral dilemmas}

There is a long tradition in ethics and logic that denies that dilemmas expressed with weak necessity modals are inconsistent, that is, that permits that 'Should $\phi$ ' and 'Should $\psi$ ', where ' $\phi$ ' and ' $\psi$ ' are contraries, can both be true. ${ }^{9}$ Suppose you have promised Alice that you would help her move and have also promised Bert that you would help him move, but then discover that you cannot help them both. Suppose also that each promise is uniquely important and that there is no higherorder principle you can use to resolve who to help. Many find it plausible that the dilemma in (17) expressed with 'should' is consistent in a way that the dilemma in

\footnotetext{
${ }^{9}$ See, e.g., Lemmon 1962; van Fraassen 1973; Williams 1973; Marcus 1980; Foot 1983; Gowans 1987; Harman 1993; Horty 1994, 2003; Goble 2009. For recent discussion in the context of ordering semantics and premise semantics, see Swanson 2011.
} 
(18) expressed with 'must' is not.

(17) I should help Alice and I should help Bert, but I can't help them both.

(18) \#I must help Alice and I must help Bert, but I can't help them both.

For the sake of argument, let's suppose that even if, fortuitously, there are no (moral) dilemmas, dilemmas expressed with 'should' are at least consistent, that is, that they are not ruled out simply by the meaning of 'should'.

One way of capturing this is by having a semantics for 'should' that does not validate agglomeration, or that does not treat 'Should $\phi$ ' and 'Should $\psi$ ' as jointly entailing 'Should $\phi \wedge \psi$ '. Treating 'must' as an ordinary necessity modal, we predict that 'must' validates agglomeration and thus that dilemmas expressed with 'must' are inconsistent. But our weaker semantics for 'should' allows for the possibility of consistently expressed dilemmas with 'should'. Roughly, 'Should $\phi$ ' and 'Should $\psi$ ', for contraries ' $\phi$ ' and ' $\psi$ ', can both be true if (and only if) there exist relevant sets $C_{g(w)}^{\prime}$ and $C_{g(w)}^{\prime \prime}$ such that 'Must $\phi$ ' is true relative to $\left(\cap\left(f(w) \cup C_{g(w)}^{\prime}\right), \lesssim g(w)\right)$, and 'Must $\psi$ ' is true relative to $\left(\cap\left(f(w) \cup C_{g(w)}^{\prime \prime}\right), \lesssim g(w)\right)$. It is interesting that, though our analyses were motivated on quite different grounds, the semantics offered here reduces to the semantics for 'ought' in Swanson 2011 (or an adaptation of it with the limit assumption) if $\bigcap\left(f(w) \cup C_{g(w)}\right)$ is a maximal $\lesssim_{g(w)}$ chain ( $c f$. also Horty 2003). (With the limit assumption, his analysis would treat 'ought' as universally quantifying over the maximal elements of some $\lesssim_{g(w)}$ chain. A $\lesssim$ chain is a totally preordered subset of a partial preorder $\lesssim$ of a set of worlds; a maximal $\lesssim$ chain is a $\lesssim$ chain that is not a proper subset of any other $\lesssim$ chain.) My semantics thus has the advantage of capturing a wider range of idea while subsuming his as a limiting case.

\subsubsection{Epistemic readings}

Though we have been focusing on teleological and deontic readings, the proposed analysis generalizes across modal flavors, even to epistemic modals. It is common to view the ordering source used in the interpretation of epistemic modals as stereotypical or evidential, or as consisting of propositions describing the usual or expected course of events (see, e.g., Kratzer 1981a: 45-47, 1991: 643-645). Like norms and goals, what is expected given certain evidence can be conditional, conditional on things being normal in the relevant respects. Suppose Alice is coming to visit and her flight was due to arrive fifteen minutes ago. The ordering source might contain a proposition like that Alice arrives by time $t^{\prime}$ if $C_{e}$ she leaves her house at time $t$, traffic conditions are thus-and-so, her flight does not get delayed, pirates do not kidnap her along the way, and so on. Thus in order for the proposition that Alice has arrived by now to be an epistemic necessity with respect to this ordering source, the 
Modality, weights, and inconsistent premise sets

modal base must be restricted to worlds in which the $\mathrm{AC} C_{e}$ is satisfied.

Consider the dialogues in (19).

a. Me: Alice must have arrived by now.

You: Really? But what if she got into a car accident on the way to the airport, or her flight got delayed, or the plane needed to circle?

Me: Oh, I hadn't thought of that. (/I was assuming otherwise.)

b. Me: Alice should have arrived by now.

You:\#But what if she got into a car accident on the way to the airport, or her flight got delayed, or the plane needed to circle?

Me: I know; that's why I said should!

As in the case of Martha and Alice in $§ 5.2 .3$, your utterance in (19a) is felicitous only if you have the epistemic authority to make me accommodate, to make it common ground by your utterance that $C_{e}$ is satisfied. If you do not, I may reasonably raise to salience certain live possibilities that are incompatible with $C_{e}$. But if I use 'should', as in (19b), your mentioning such possibilities may be beside the point. In using 'should', I am not committing to the truth of $C_{e}$; I am making a subjunctive claim about what would be necessary were it to turn out that $C_{e}$ holds. In general, 'must' will be preferred if I can reasonably treat $C_{e}$ as settled, and 'should' will be preferred if I cannot. In this way, our analysis can provide a uniform explanation for the behavior of weak and strong necessity modals that generalizes across modal flavors.

\subsubsection{Factivity and performativity}

The subjunctive element of weak necessity modals suggests an explanation for seemingly unrelated puzzles concerning the (non-)factivity and (non-)performativity of 'should' and 'must'.

First, though many authors have claimed that 'Should $\phi$ ' on its epistemic reading expresses that $\phi$ is probable, ${ }^{10}$ the data strongly suggests that 'should' is unlike 'must' in this respect.

a. Alice should be here by now, but she isn't.

b. \#Alice must be here by now, but she isn't.

In credence talk, 'Must $\phi$ ' seems to commit the speaker to a high (unconditional) credence in $\phi$, whereas 'Should $\phi$ ' does not seem to commit the speaker to any (unconditional) credence in $\phi .{ }^{11}$ 'Must $\phi$, but $\neg \phi$ ' appears to be inconsistent in a way that 'Should $\phi$, but $\neg \phi$ ' is not. Surprisingly, this appears to hold for deontic

\footnotetext{
${ }^{10}$ E.g., Sloman 1970; Horn 1972; Wertheimer 1972; Finlay 2009; Lassiter 2011.

${ }^{11}$ Cf. Coates 1983: pp. 65, 74, 82; Palmer 1990: pp. 59-60; Swanson 2012.
} 
Alex Silk

readings as well. ${ }^{12}$

a. You should help your mother, but you won't (/but I know you won't).

b. \#You must help your mother, but you won't (/but I know you won't).

Of course, obligations can go unfulfilled. However, speakers appear to rule out this possibility - at least for the purposes of the conversation — when expressing obligations with 'must'.

Our analysis has a natural explanation for these data. Start with 'should'. 'Should $\phi$ ' makes a subjunctive claim about what would be necessary were it to turn out that certain ACs are satisfied. $\phi$ need not be necessary with respect to what is settled in the actual context; in order for $\phi$ to be necessary, the modal base $\bigcap f(w)$ must be restricted to worlds in $\bigcap \mathcal{C}_{g(w)}$. So, for all that is being presupposed, the set of best worlds - the modal's domain of quantification - might not be a subset of the common ground. If it is not, $\neg \phi$ might be true throughout the common ground - hence the consistency of (20a) and (21a). Thus, our analysis, combined with the cross-linguistic data from von Fintel \& Iatridou 2008, provides independent support for the view that the subjunctive presupposes (implicates, asserts) that the modal's domain of quantification might not be a subset of the common ground. ${ }^{13}$

'Must', by contrast, does not have a subjunctive element to its meaning. The truth of 'Must $\phi$ ' requires that the relevant ACs are actually satisfied. If von Fintel 1998 is right that there is a default presupposition that the domain of quantification is a subset of the common ground (see n. 13), we have straightaway an explanation for the inconsistency of (20b) and (21b). Since 'must' is not subjunctive it does not signal that this default might not hold; hence the set of best worlds must be included in the common ground; hence it cannot be that the negation of the prejacent holds throughout the common ground; hence the inconsistency of 'Must $\phi$, but $\neg \phi$ '. In these ways, even if Swanson (2012: 22-23) is right that "pure premise semantics" - equivalently, pure ordering semantics (Lewis 1981) — "on its own" cannot capture the data in (20) (or in (21), we might add), the analyses of 'must' and 'should' in $\$ 5.1$, conjoined with independently motivated pragmatic constraints on mood and the interpretation of modals, suggest one natural explanation.

Second, related to the data in (20) and (21) is the point that weak and strong necessity modals are often thought to differ in their conventional force. At least in root clauses, 'must', unlike 'should', is often thought to have a performative or

${ }^{12}$ See esp. Werner 2003: 124-137; Ninan 2005; Portner 2009: 103, 189-196; cf., e.g., Lemmon 1962; Wertheimer 1972; Harman 1973; Lyons 1977; Williams 1981; Coates 1983; Palmer 1990, 2001.

${ }^{13}$ See, e.g., Stalnaker 1975; von Fintel 1998. According to von Fintel 1998, there is a default presupposition that the domain of quantification is a subset of the common ground, and the subjunctive signals that this default fails to hold. I have weakened this pragmatic constraint on the subjunctive so that it signals only that this default presupposition might not hold. 
Modality, weights, and inconsistent premise sets

imperative-like aspect to its conventional meaning, conventionally performing a directive speech act or establishing a new ideal (perhaps in addition to performing an assertion). ${ }^{14}$ Our analysis can explain these discourse properties of 'must' and 'should', and can do so without having to resort to a dynamic implementation (though such an implementation might be desirable on other grounds). The performative properties of 'must' follow from the fact explained above that acceptance of 'Must $\phi$ ' is incompatible with a denial of ' $\phi$ '. So, if ' $\phi$ ' describes a future-oriented action or state of affairs under the control of the addressee, updating with 'Must $\phi$ ' commits the addressee to making ' $\phi$ ' true - hence the performativity of 'must'. By contrast, since acceptance of 'Should $\phi$ ' is compatible with the denial of ' $\phi$ ', updating with 'Should $\phi$ ' does not conventionally restrict the common ground to $\phi$-worlds, and so need not commit the interlocutors to making ' $\phi$ ' true. So, even if 'should' can be used to perform a directive speech act, it does not do so as a matter of its conventional meaning.

\section{6 'Ought', 'must', and the common ground}

Before concluding, I would like to briefly compare my account with another recent account of the weak/strong necessity distinction, Aynat Rubinstein's, mentioned in \$5.1. (Since her $2012 \mathrm{~b}$ is not yet publicly available, I will not be referencing the developments of her view in that work. All page references will be to her 2011.)

According to Rubinstein, as I understand her, the apparent distinction between von Fintel \& Iatridou's primary and secondary ordering sources is in fact a distinction between considerations that are and are not currently accepted in the discourse common ground. 'Should' and 'must' are both given an "ordinary Kratzerian semantics of necessity" (144) and are claimed to differ only in their non-truthconditional content. (She focuses on 'ought', but, consistent with our discussion, I will continue to focus on 'should'.) For 'Must $\phi$ ' to be felicitous, the truth of the necessity claim cannot depend on considerations not accepted in the common ground; 'must' quantifies only over the best worlds as determined by the conversationally agreed upon values of modal base and ordering source. (Agreed upon when? Rubinstein does not say, but I would assume that it is after the statement has been made (Stalnaker 1978, 1998, 2002), lest 'Must $\phi$ ' never be controversial or news.) By contrast, 'should' carries a special conventional signal, "SigW," that the truth of the necessity claim depends on assumptions that outstrip the common ground - more precisely, that the modal must be interpreted with respect to a superset of $f_{c g}(w)$ of $g_{c g}(w)$. (To make room for examples like (3a), I assume this may be an improper superset.) Rubinstein argues that this signal is a type of conventional meaning

${ }^{14}$ For recent discussion, see especially Ninan 2005; Portner 2007: 363-365, 2009: 103-105, 189-196; Swanson 2008: 1203-1204. 
that is "projective, not-at-issue, antibackgrounding in a sense, and grammatically determined. Thus, it is most similar to a type of presupposition that is nonetheless not pre-supposed or backgrounded in any intuitive sense" (2011: 141).

As noted above, Rubinstein nicely highlights previously underappreciated sensitivities to common ground assumptions in 'should' and 'must'. However, I am unclear on certain of the data she cites and whether there is independent evidence for the type of non-truth-conditional meaning component she posits. For reasons of space I cannot detail these concerns here. My aim here is only to make a preliminary case that the the analysis in $\$ 5$ more perspicuously explains certain properties Rubinstein ascribes to weak necessity modals.

First, whereas Rubinstein posits a special, primitive conventional signal for 'should' concerning speaker commitments and standing assumptions, the analysis in this paper can avoid doing so. The alleged discourse properties of 'should' can be explained in terms of its truth-conditional content and familiar pragmatic norms. It is a commonplace that utterances express speakers' states of mind. My utterance of 'Alice committed the murder' expresses my belief that Alice committed the murder. But my utterance of 'If Alice was in the house, she committed the murder' does not express this belief; it only expresses my belief that Alice committed the murder on the supposition that Alice was in the house. That utterances of 'Should $\phi$ ' should express that the necessity of $\phi$ depends on considerations not currently accepted (even after the utterance) is unsurprising on my account: It follows from the suppositional nature of the truth conditions of 'should' and pragmatic norms associated with such suppositions, along with the familiar point that assertions express speakers' commitments to their contents. 'Should $\phi$ ' expresses something about speaker commitments simply because it is a sentence with a certain content; it expresses the commitment that it does, with its particular relation to the common ground, because of the suppositional nature of that content. Since conventions are, in a sense, essentially arbitrary, an account which derived a signal like SigW from the truth conditions 'should' and more general, independently attested conversational principles may be more explanatory and less stipulative, and thus preferable. ${ }^{15}$

Second, since 'should' and 'must' make the same contribution to truth conditions on Rubinstein's account (given an analysis like in Def. 3), it appears that she is unable to capture the consistency of dilemmas of expressed with 'should' (\$5.2.4).

Finally, on my account, it is only the modal base which is updated in the

\footnotetext{
${ }^{15}$ As for SigW's alleged projective properties, the data Rubinstein cites is, as she grants, shaky at best. I am skeptical about whether SigW passes the "Family of Sentences" tests (e.g., Karttunen 1974; Chierchia \& McConnell-Ginet 1990) as Rubinstein claims. It seems to me that the analysis in $\$ 5$ better captures the behavior of 'should' when embedded - e.g., why Rubinstein's posited signal cannot be globally satisfied under attitude verbs - and in familiar upper-bounding scalar implicatures, but, again, I must reserve discussion of this for elsewhere.
} 
Modality, weights, and inconsistent premise sets

interpretation of 'should'. By contrast, on Rubinstein's account, the non-commonground assumptions with respect to which 'should' is interpreted can figure in the modal base or ordering source. However, we have already seen $(\$ 5.1)$ that there is good evidence that, even in the case of teleological and deontic modals, the extra assumptions are factual ones. Of course, speakers can utter 'should' sentences the truth of which depends on premises in the ordering source that are controversial or not yet settled in the conversation. But this does not mark a difference with 'must'. To elucidate the weak/strong necessity distinction, we need to look at cases where 'should' is preferred to 'must' and vice versa. Such cases, we have seen, suggest that the difference lies in the modal base, not the ordering source.

\section{Conclusion}

Little work has been devoted to the distinction between weak and strong necessity modals. In this paper I have offered an analysis of this distinction that makes intuitively correct predictions concerning various semantic and pragmatic properties of weak and strong necessity modals. On this analysis, weak necessity modals express a kind of conditional necessity, necessity on the supposition that the ACs of certain norms, goals, etc. are satisfied. This analysis helps illuminate the crucial role that expressions of weak necessity play in conversation, thought, and planning.

\section{References}

Anderson, Alan Ross. 1951. A note on subjunctive and counterfactual conditionals. Analysis 11. 35-38.

Bybee, Joan, Revere Perkins \& William Pagliuca. 1994. The evolution of grammar: Tense, aspect, and modality in the languages of the world. Chicago: University of Chicago Press.

Chierchia, Gennaro \& Sally McConnell-Ginet. 1990. Meaning and grammar: An introduction to semantics. MIT Press: Cambridge.

Coates, Jennifer. 1983. The semantics of the modal auxiliaries. London: Croom Helm.

Copley, Bridget. 2006. What should should mean? MS, CNRS/Université Paris 8.

Finlay, Stephen. 2009. What ought probably means, and why you can't detach it. Synthese 177. 67-89.

von Fintel, Kai. 1998. The presupposition of subjunctive conditionals. In Uli Sauerland \& Orin Percus (eds.), MIT working papers in linguistics: The interpretive tract, vol. 25, Cambridge: MIT Press.

von Fintel, Kai \& Sabine Iatridou. 2005. What to do if you want to go to Harlem: Anankastic conditionals and related matters. MS, MIT. 
von Fintel, Kai \& Sabine Iatridou. 2008. How to say ought in foreign: The composition of weak necessity modals. In Jacqueline Gueron \& Jacqueline Lecarme (eds.), Time and modality, 115-141. Springer.

Foot, Philippa. 1983. Moral realism and moral dilemma. The Journal of Philosophy 80. 379-398.

van Fraassen, Bas C. 1973. Values and the heart's command. The Journal of Philosophy 70. 5-19.

Gamut, L.T.F. 1991. Logic, language, and meaning, Volume 1: Introduction to logic. Chicago: University of Chicago Press.

Gazdar, Gerald. 1979. Pragmatics: Implicatures, presupposition, and logical form. New York: Academic Press.

Goble, Lou. 2009. Normative conflicts and the logic of 'ought'. Nous 43. 450-489. Gowans, Christopher W. (ed.). 1987. Moral dilemmas. New York: Oxford University Press.

Hare, R.M. 1952. The language of morals. Oxford: Oxford University Press.

Harman, Gilbert. 1973. Review of Roger Wertheimer, The significance of sense: Meaning, modality, and morality. The Philosophical Review 82. 235-239.

Harman, Gilbert. 1975. Reasons. Crítica: Revista Hispanoamericana de Filosofía 7. 3-17.

Harman, Gilbert. 1993. Stringency of rights and "ought". Philosophy and Phenomenological Research 53. 181-185.

Horn, Laurence R. 1972. On the semantic properties of logical operators in English: University of California, Los Angeles Ph.d. thesis.

Horn, Laurence R. 1989. A natural history of negation. Chicago: University of Chicago Press.

Horty, John F. 1994. Moral dilemmas and nonmonotonic logic. Journal of Philosophical Logic 23. 35-65.

Horty, John F. 2003. Reasoning with moral conflicts. Nous 37. 557-605.

Iatridou, Sabine. 2000. The grammatical ingredients of counterfactuality. Linguistic Inquiry 31(2). 231-270.

Jones, Andrew J.I. \& Ingmar Pörn. 1986. 'Ought' and 'must'. Synthese 66. 89-93.

Kant, Immanuel. 1956. Groundwork of the metaphysics of morals Paton, H.J. (Trans.). New York: Harper \& Row 3rd edn.

Karttunen, Lauri. 1974. Presupposition and linguistic context. Theoretical linguistics 1. 181-194.

Kratzer, Angelika. 1977. What 'must' and 'can' must and can mean. Linguistics and Philosophy 1. 337-355.

Kratzer, Angelika. 1981a. The notional category of modality. In Hans Jurgen Eikmeyer \& Hannes Rieser (eds.), Words, worlds, and contexts. New approaches in word semantics, 38-74. Berlin: de Gruyter. 
Modality, weights, and inconsistent premise sets

Kratzer, Angelika. 1981b. Partition and revision: The semantics of counterfactuals. Journal of Philosophical Logic 10. 201-216.

Kratzer, Angelika. 1991. Modality/Conditionals. In A. von Stechow \& D. Wunderlich (eds.), Semantics: An international handbook of contemporary research, 639-656. Berlin: de Gruyter.

Lassiter, Daniel. 2011. Measurement and modality: The scalar basis of modal semantics: New York University dissertation.

Lemmon, E.J. 1962. Moral dilemmas. Philosophical Review 71(2). 139-158.

Lewis, David. 1973. Counterfactuals. Cambridge: Harvard University Press.

Lewis, David. 1979. Scorekeeping in a language game. Journal of Philosophical Logic 8. 339-359.

Lewis, David. 1981. Ordering semantics and premise semantics for counterfactuals. Journal of Philosophical Logic 10(2). 217-234.

Lyons, John. 1977. Semantics, vol. 2. Cambridge: Cambridge University Press.

Marcus, Ruth Barcan. 1980. Moral dilemmas and consistency. Journal of Philosophy 78. 121-136.

McNamara, Paul. 1996. Must I do what I ought? (Or will the least I can do do?). In Mark A. Brown \& José Carmo (eds.), Deontic logic, agency, and normative systems, 154-173. Berlin: Springer-Verlag.

Ninan, Dilip. 2005. Two puzzles about deontic necessity. In Jon Gajewski, Valentine Hacquard, Bernard Nickel \& Seth Yalcin (eds.), MIT working papers in linguistics: New work on modality, vol. 51, 149-178.

Palmer, F.R. 1990. Modality and the english modals. New York: Longman 2nd edn.

Palmer, F.R. 2001. Mood and modality. Cambridge: Cambridge University Press 2nd edn.

Portner, Paul. 2007. Imperatives and modals. Natural Language Semantics 15(4). 351-383.

Portner, Paul. 2009. Modality. Oxford: Oxford University Press.

Ross, W.D. 1930. The right and the good. Oxford: Oxford University Press.

Rubinstein, Aynat. 2011. Projective signals of weak necessity modals. In Gregory Kierstead (ed.), ESSLLI 2011: Workshop on projective content, 141-155. Ljubljana.

Rubinstein, Aynat. 2012a. Figuring out what we ought to do. Poster for the Penn Linguistics Colloquium (PLC 36).

Rubinstein, Aynat. 2012b. Roots of modality: University of Massachusetts Ph.d. thesis.

Sloman, Aaron. 1970. 'Ought' and 'better'. Mind 79. 385-394.

Stalnaker, Robert. 1975. Indicative conditionals. In Stalnaker (1999) 63-77.

Stalnaker, Robert. 1978. Assertion. In Stalnaker (1999) 78-95.

Stalnaker, Robert. 1998. On the representation of context. In Stalnaker (1999) 
96-113.

Stalnaker, Robert. 1999. Context and content: Essays on intentionality in speech and thought. Oxford: Oxford University Press.

Stalnaker, Robert. 2002. Common ground. Linguistics and Philosophy 25. 701-721. von Stechow, Arnim, Sveta Krasikova \& Doris Penka. 2006. Anankastic conditionals again. In Torgrim Solstad, Atle Gronn \& Dag Haug (eds.), Festschrift for Kjell Johann Saebo, Oslo.

Swanson, Eric. 2008. Modality in language. Philosophy Compass 3(6). 1193-1207.

Swanson, Eric. 2011. On the treatment of incomparability in ordering semantics and premise semantics. Journal of Philosophical Logic 40. 693-713.

Swanson, Eric. 2012. The application of constraint semantics to the language of subjective uncertainty. Journal of Philosophical Logic 1-28.

Veltman, Frank. 1976. Prejudices, presuppositions, and the theory of conditionals. In Jeroen Groenendijk \& Martin Stokhof (eds.), Amsterdam papers in formal grammar, vol. 1, 248-281. Central Interfaculteit, University of Amsterdam.

Werner, Thomas A. 2003. Deducing the future and distinguishing the past: Temporal interpretation in modal sentences in English: Rutgers University Ph.d. thesis.

Wertheimer, Roger. 1972. The significance of sense: Meaning, modality, and morality. Ithaca: Cornell University Press.

Williams, Bernard. 1973. Ethical consistency. In Problems of the self, 166-186. Cambridge: Cambridge University Press.

Williams, Bernard. 1981. Practical necessity. In Moral luck, 124-131. Cambridge: Cambridge University Press.

\footnotetext{
Alex Silk

University of Michigan

Department of Philosophy

$435 \mathrm{~S}$ State $\mathrm{St}$

2215 Angell Hall

Ann Arbor, MI 48109-1003

asilk@umich.edu
} 